\title{
Quality of Life Following Hemicraniectomy for Malignant MCA Territory Infarction
}

\author{
Alexander G. Weil, Ralph Rahme, Robert Moumdjian, Alain Bouthillier, \\ Michel W. Bojanowski
}

\begin{abstract}
Objective: Decompressive hemicraniectomy (DH) has been shown to reduce mortality in patients with malignant middle cerebral artery (MCA) territory infarction. However, many patients survive with moderate-to-severe disability and controversy exists as to whether this should be considered good outcome. To answer this question, we assessed the quality of life (QoL) of patients after DH for malignant MCA territory infarction in our milieu. Methods: The outcome of all patients undergoing DH for malignant MCA territory infarction between 2001 and 2009 was assessed using retrospective chart analysis and telephone follow-up in survivors. Functional outcome was determined using Glasgow outcome scale, modifed Rankin scale (mRS), and Barthel index (BI). The stroke impact scale was used to assess QoL. Results: There were 14 patients, 6 men and 8 women, with a mean age of 44 years (range 27-57). All patients had reduced level of consciousness preoperatively. Five had dominant-hemisphere stroke. Median time to surgery was 45 hours (range 1- 96). Two patients died and one was lost to follow-up. Of 11 survivors, 7 (63.6\%) had a favorable functional outcome (mRS<4). No patient was in persistent vegetative state. Despite impaired QoL, particularly in physical domains, the majority of interviewed patients and caregivers ( 7 of 8), including those with dominant-hemisphere stroke, were satisfied after a median follow-up of 18 months (range 6-43). Conclusion: Most patients report satisfactory QoL despite significant disability even in the face of moderate-to-severe disability and dominant-hemsiphere stroke. Dominant-hemisphere malignant MCA territory infarction should not be considered a contraindication to $\mathrm{DH}$.
\end{abstract}

RÉSUMÉ: La qualité de vie après l'hémicraniectomie suite à un infarctus malin dans le territoire de l'artère cérébrale moyenne. Objectif : Il a été bien démontré que l'hémicraniectomie décompressive (HD) diminue la mortalité chez les patients qui ont subi un infarctus malin dans le territoire de l'artère cérébrale moyenne $(\mathrm{ACM})$. Plusieurs des patients qui survivent présentent une invalidité de modérée à sévère. Il existe une controverse à savoir ce qui devrait être considéré comme étant un bon résultat. Nous avons évalué la qualité de vie (QV) de patients après une HD effectuée suite à un infarctus malin dans le territoire de l'ACM dans notre milieu. Méthode : Nous avons évalué le résultat chez tous les patients ayant subi une HD suite à un infarctus malin dans le territoire de l'ACM entre 2001 et 2009 au moyen d'une analyse rétrospective de dossier et un suivi téléphonique chez les survivants. Nous avons déterminé le résultat fonctionnel au moyen de la Glasgow outcome scale, de la modified Rankin scale (mRS) et du Bartel index (BI) et la QV au moyen de la Stroke Impact Scale. Résultats : Nous avons identifié 14 patients, 6 hommes et 8 femmes, dont l'âge moyen était de 44 ans (écart de 27 à 57 ans). Tous les patients avaient un niveau de conscience diminué avant la chirurgie. Cinq avaient subi un accident vasculaire cérébral de l'hémisphère dominant. L'intervalle médian entre l'événement et la chirurgie était de 45 heures (écart de 1 à 96 heures). Deux patients sont décédés et 1 patient n'a pas pu être rejoint pour le suivi. Parmi les 11 survivants, l'issue fonctionnelle a été favorable chez 7 patients (63,6\%), soit un score mRS $<4$. Aucun patient n'était dans un état végétatif persistant. La majorité des patients dont nous avons fait l'entrevue et des soignants (7 de 8), incluant ceux qui avaient subi un AVC à l'hémisphère dominant, étaient satisfaits après un suivi médian de 18 mois (écart de 6 à 43 mois) malgré une QV altérée, particulièrement dans les domaines physiques. Conclusion : La plupart des patients rapportent une QV satisfaisante malgré une invalidité significative, même ceux qui présentent une invalidité de modérée à sévère et un AVC de l'hémisphère dominant. Un infarctus malin de l'ACM de l'hémisphère dominant ne devrait pas être considéré comme une contre-indication à l'HD.

Can. J. Neurol. Sci. 2011; 38: 434-438

Extensive middle cerebral artery (MCA) territory infarction may affect up to $10 \%$ of patients with a supratentorial ischemic stroke and, in most cases, leads to malignant MCA territory infarction ${ }^{1,2}$. Under conservative treatment, malignant MCA territory infarction is associated with $80 \%$ mortality, usually as a result of transtentorial herniation secondary to massive cytotoxic edema and increased intracranial pressure (ICP) ${ }^{1,3}$.

Recently, the pooled analysis of three European randomized controlled trials (RCTs) demonstrated that early decompressive hemicraniectomy $(\mathrm{DH})$ in well-selected patients may significantly reduce mortality without increasing the number of patients in a persistent vegetative state ${ }^{4-7}$. However, most survivors will have some degree of neurological sequelae and a significant proportion will have moderate-to-severe disability.

From the Division of Neurosurgery, Hôpital Notre-Dame du CHUM, University of Montreal, Montreal, Quebec, Canada.

Received August 16, 2010. Final Revisions Submitted January 10, 2011. Correspondence to: Michel W. Bojanowski, Division of Neurosurgery, Hôpital NotreDame du CHUM, 1560 Sherbrooke E, Montreal, Quebec, H2L 4M1, Canada. 
Whether these patients with a modified Rankin scale (mRS) score of 4 may be considered to have a good outcome is still a matter of debate ${ }^{8-11}$. When assessing outcome, one should take into account the impact of treatment on quality of life $(\mathrm{QoL})^{12}$. While functional outcome has been extensively studied in these patients, very few publications have focused on their healthrelated QoL (HRQoL).

Unlike functional outcome, HRQoL is strongly influenced by socio-cultural factors ${ }^{13}$ and findings in one population may not be readily generalizable to others. Unfortunately, there is a significant lack of studies to support the assumption that satisfactory HRQoL is a universal finding following $\mathrm{DH}$ for malignant MCA territory infarction. Therefore, in an attempt to add to the pre-existing literature, we reviewed our experience and sought to determine the HRQoL following this procedure in our milieu.

\section{Patients And Methods}

\section{Patient Selection}

In our institution, patients younger than 60-years-old with good previous QoL and computed tomogram (CT)-documented extensive MCA territory infarction are considered potential candidates for DH. It has always been our policy to consider DH for relatively young patients with malignant MCA territory infarction. Given their low likelihood of achieving a satisfactory functional outcome, patients older than 60 years were not routinely offered surgery. Since their publication in 2007, the results of the European pooled analysis ${ }^{6}$ have lent further support to our policy of recommending $\mathrm{DH}$ for patients younger than 60 years.

Infarction is considered to be extensive when two-thirds of the MCA territory is affected, with or without involvement of the anterior cerebral artery (ACA) and/or posterior cerebral artery (PCA) territories. Dominant hemisphere strokes do not constitute an absolute contraindication for this procedure. Patients are usually monitored in the intermediate neurointensive care unit where a detailed discussion regarding the benefits, risks, and expected functional outcome following $\mathrm{DH}$ is undertaken with them and their families. All patients receive medical treatment aimed at reducing the ICP, including bed rest, head elevation, analgesia, and osmotic diuresis. For consenting patients, DH is performed as soon as deterioration of the level of consciousness occurs along with CT evidence of increased ICP and mass effect, despite maximal medical therapy.

\section{Surgical Management}

The technique of DH for malignant MCA territory infarction has been well described in previous publications ${ }^{14-16}$. In summary, a trauma flap skin incision is performed and a large fronto-temporo-parietal bone flap is removed extending from the floor of the middle fossa laterally to within one $\mathrm{cm}$ of the sagittal suture medially, and from the floor of the anterior fossa anteriorly to approximately five to six $\mathrm{cm}$ behind the pinna posteriorly. The dura is incised widely in a cruciate manner allowing the swollen brain to relax. At this point, a loose duraplasty is fashioned using either autologous pericranium or a synthetic dural patch and an intraparenchymal ICP monitor is inserted at the discretion of the operating surgeon. Occasionally, in cases where cerebral edema is extremely severe and ICP is difficult to control, additional procedures such as external ventricular drainage (EVD) or resection of infarcted brain tissue may be performed. Post-operatively, patients are transferred back to the neurointensive care unit where ICP monitoring and medical management (target ICP $<20 \mathrm{~mm} \mathrm{Hg}$, target cerebral perfusion pressure $>60 \mathrm{~mm} \mathrm{Hg}$ ) are undertaken.

\section{Study Methodology}

All patients who underwent DH for malignant MCA territory infarction between January 2001 and April 2009 in our institution were included in this retrospective cohort analysis. Medical records were reviewed and the following variables were recorded: sex, age, other demographic factors, medical comorbidities, etiology of stroke, time from symptom onset to surgery, preoperative neurological condition, type of procedure, timing of cranioplasty, and duration of follow-up. Telephone follow-up was obtained with the survivors when possible. Otherwise, their neurological condition at their most recent office visit was recorded. Outcome measures included 30-day survival, residual neurological deficits, Glasgow outcome scale (GOS) and mRS scores ${ }^{17}$, the Barthel index $(\mathrm{BI})^{18}$, the stroke impact scale version 3.0 (SIS3) $)^{19-22}$, and patient satisfaction. Functional outcome was considered to be favorable when patients had GOS 4 or 5 , mRS 3 or less, BI $>60$ and were not institutionalized. In regards to HRQoL, SIS3 consists of eight domains: four physical (strength, hand function, mobility, and activities of daily living) and four psychosocial (emotion, communication, memory, and social participation), and includes the patient's global assessment of the percentage of recovery. The score of each domain ranges from 0 (worst) to 100 (best). Patient satisfaction was assessed by asking the patient or his primary caregiver whether he/she regrets having undergone DH. The study was approved by the hospital's ethics committee.

\section{Results \\ Study Population}

The study population consisted of 14 patients, 6 males and 8 females, with a median age of 44 years (range 27-57). Etiology of malignant MCA territory infarction was MCA or internal carotid artery (ICA) thrombosis in seven patients, ICA dissection in three patients, MCA embolism in two patients, and iatrogenic MCA or ICA occlusion (arterio-arterial embolism after elective non-ruptured aneurysm clipping) in two patients. Infarction extended to the anterior cerebral artery territory in one patient and involved the basal ganglia in nine. The right hemisphere was involved in 11 patients, while three had a left hemispheric stroke. All patients had hemiplegia or profound hemiparesis preoperatively and five had global aphasia (including two lefthanded patients with a right hemispheric stroke). All patients exhibited deterioration of their level of consciousness preoperatively as a result of mass effect. The median time from ictus to surgery was 45 hours (range 1- 96). All patients underwent DH with duraplasty and four had an intraparenchymal ICP monitor inserted. One patient with particularly severe cerebral edema and refractory increased ICP required external ventricular drain placement and temporopolar lobectomy. 


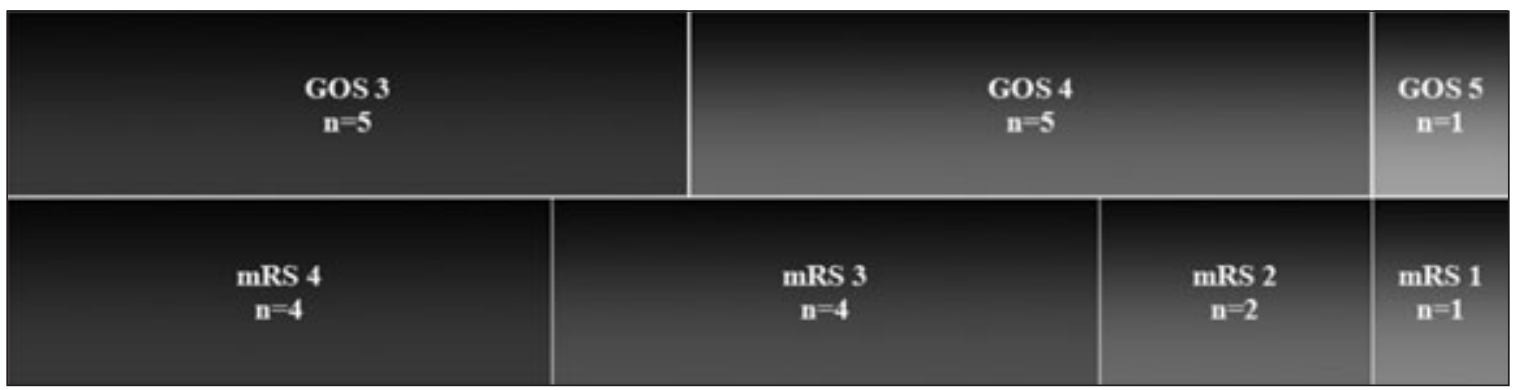

Figure 1: Functional outcome of survivors $(N=11)$

\section{Functional Outcome}

Two patients (14.3\%) died during the acute phase as a result of pulmonary embolism in one patient and unexplained cardiorespiratory arrest in the other. Of the 12 survivors (85.7\%), one was lost to follow-up after being transferred back to his foreign country of origin. The remaining 11 patients were available for functional outcome assessment. After a median follow-up of 27 months (range 1-72), six patients (54.5\%) had GOS 4 or 5 and $7(63.6 \%)$ had mRS 3 or less. In addition, six (75\%) of eight patients with available BI had a score $>60$. There were no patients in persistent vegetative state (Figure 1). Of eight patients available for motor function assessment, seven (87.5\%) exhibited improvement of lower extremity strength and four
(50\%) showed improved upper extremity strength, while only one patient $(12.5 \%)$ had useful hand function at the time of follow-up. All four survivors with global aphasia had regained some comprehension of spoken language, although they had varying degrees of residual expressive aphasia. None of the patients were able to return to their previous occupation and two were still institutionalized at their last follow-up.

\section{Quality of Life}

Eight of 11 patients were available for HRQoL assessment through telephone interview (Figure 2). Two patients were lost to follow-up after their last office visit and one had died from systemic cancer. Stroke impact scale version 3.0 was

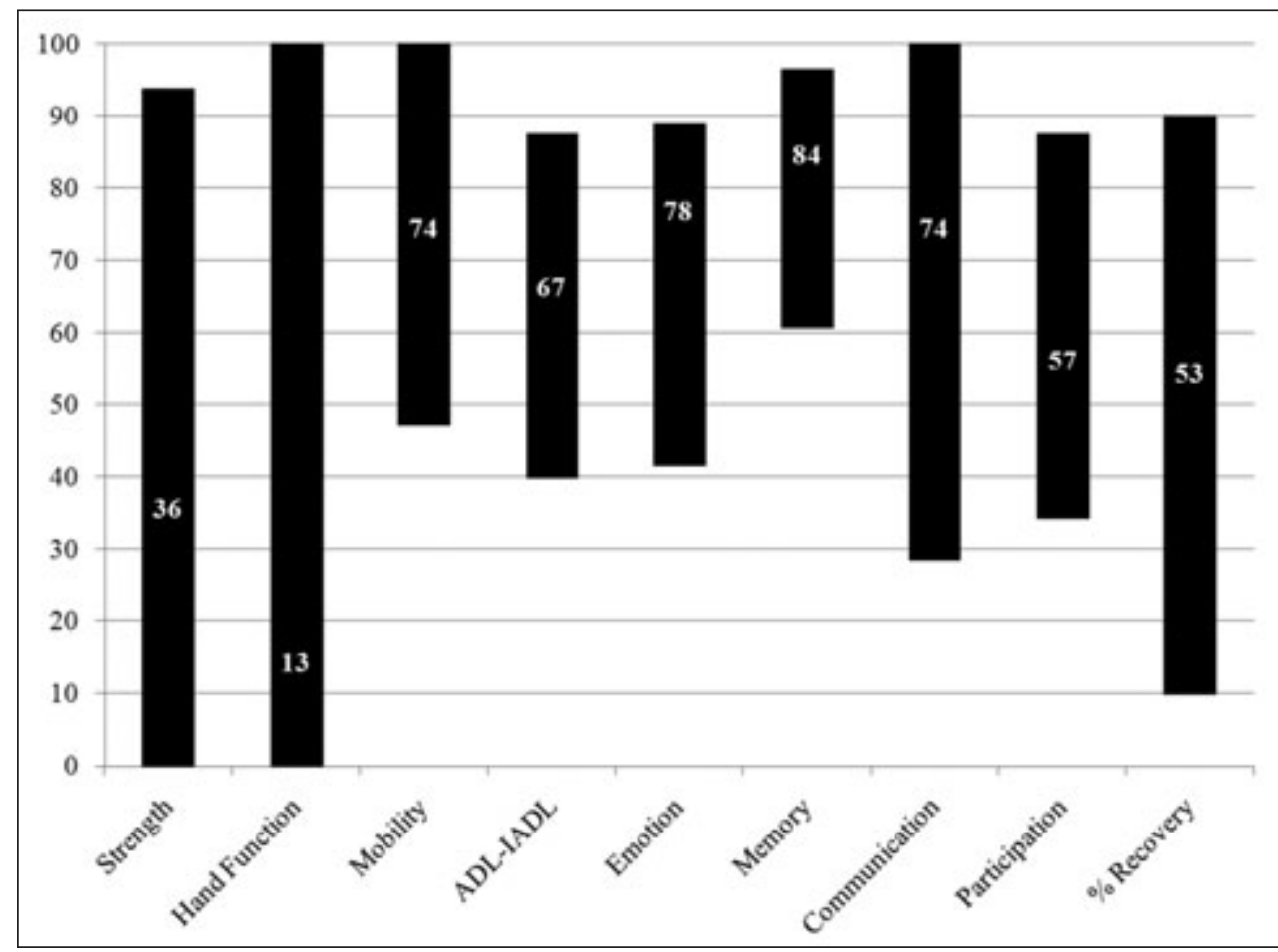

Figure 2: Health-related quality of life $(N=8)$. Boxes represent the score range for each of the nine SIS3 domains. Numbers inside boxes represent the mean score for each domain. ADL=Activities of daily living, $I A D L=$ Instrumental activities of daily living. 
administered to three patients and to the primary caregiver for each of the remaining five patients after a median follow-up of 18 months (range 6-43). The mean scores were highest for memory (84), emotion (78), and communication (74), and were lowest for participation (57), strength (36), and hand motor function (13). Despite decreased strength, mobility and activities of daily living were relatively maintained (mean scores 74 and 67 , respectively). Patients with dominant hemisphere infarction tended to have lower scores for communication (57 vs. 96) but higher scores for other domains such as participation (62.7 vs. 52.3), emotion (84 vs. 67.8), and memory (89 vs. 80.9). Seven patients $(87.5 \%)$ were happy to be alive and did not regret having undergone $\mathrm{DH}$, while one $(12.5 \%)$ was dissatisfied and would not have accepted to undergo this procedure for the same result. This particular patient was a previously highly functional 45year-old female who remained significantly disabled (mRS 4, BI 55) after her stroke, had urinary and fecal incontinence, was still institutionalized at her three year follow-up, and had little family support.

\section{DiscuSSION}

The purpose of this study was to determine whether the HRQoL and satisfaction rate following DH for malignant MCA territory infarction warranted its indication in our milieu. The strong influence of cultural, geographical, and anthropological factors $^{13}$ on HRQoL ${ }^{23-25}$ justifies the need to undertake multiple studies in different cultural and geographical settings and at different periods in time.

A recent pooled analysis of three randomized controlled trials $^{4-7}$ demonstrated that early DH reduces mortality from $71 \%$ to $22 \%$ in patients with malignant MCA territory infarction. Decompressive hemicraniectomy has also been shown to increase the likelihood of a favorable functional outcome by doubling the chance of living with an mRS 3 or less and tripling the chance of living with an mRS 4 or less, without increasing the number of survivors in a persistent vegetative state ${ }^{6}$. In the present series, $86 \%$ of patients survived with a favorable functional outcome (mRS 3 or less) and physical independence $(\mathrm{BI}>60)$ in $64 \%$ and $82 \%$ of survivors, respectively. However, $36 \%$ of patients survived with moderate-to-severe disability (mRS 4) suggesting that the life-saving potential of DH may come at the cost of survival in a dependent state. Moreover, survivors may exhibit severe neuro-psychological deficits, cognitive dysfunction, and high rates of depression ${ }^{4,8,11,26-29}$. Therefore, outcome should not be measured solely in terms of functional parameters. Instead, outcome assessment should incorporate the impact of deficit, functional status, cognitive function, and psychological function on patients' HRQoL ${ }^{23-25}$.

The HRQoL is a patient-centered measure allowing outcome not to be evaluated in terms of the physician's perspective of what constitutes an acceptable functional result, but rather in terms of the patient's perception of their own health status ${ }^{23-25}$, the latter being strongly affected by cultural, geographical, and anthropological factors ${ }^{13}$. To date, nine European studies and only one North American study have analyzed HRQoL following DH for malignant MCA territory infarction, 4,6,8,11,26,29-33. In the present study, HRQoL was assessed using SIS3, a self-reported stroke-specific measure that was shown to be reliable, valid, and applicable to malignant MCA territory infarction patients even

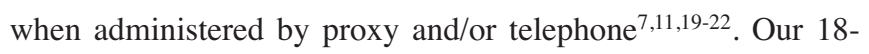
month median follow-up is relatively long compared to previous studies on HRQoL $4,6,8,11,26,29,31,33$. We found that DH survivors had reduced overall HRQoL with dysfunction predominating in the physical rather than psychosocial domains, had greater communication dysfunction in dominant-hemisphere strokes, but maintained a great $(87.5 \%)$ satisfaction rate. It is interesting to note that similar findings, including high satisfaction rates (79-100\%), are almost universally found in the literature despite different study methodologies and various HRQoL assessment scales $^{4,5,7,8,29,30,32-34}$.

Although most available literature, including the present study, suggests that HRQoL after DH for malignant MCA territory infarction is generally acceptable, whether or not this would prove to be true across the world remains to be seen. So far, all studies on HRQoL have arisen from the Western world and the reproducibility of their findings in other countries, particularly the developing world, has yet to be shown. In this small series, the only regret came from a previously highly functional young woman who had a remarkably poor functional outcome and very little family support. This example clearly illustrates how HRQoL may be affected by several variables, including the level of disability, the premorbid lifestyle, and the personality of the patient and his relatives $9,29,31,35$.

Whether DH should be offered to patients with dominant-side malignant MCA territory infarction is still a matter of debate ${ }^{10,14,15,29,30,33,36,37}$. While some authors still consider dominant-hemisphere stroke as a relative contraindication to DH given the potential for severe disability and reduced QoL because of residual aphasia ${ }^{10,14,30}$, others have documented substantial improvement of language following $\mathrm{DH}$ in these patients ${ }^{15,29,33,36,37}$ and have shown that, although communication may be severely affected in dominant-hemisphere strokes, there was no difference in functional outcome, overall HRQoL, or patient satisfaction between dominant and non dominant-side malignant MCA territory infarction ${ }^{6,7,15,29,33,36,38}$. In this series, five patients had global aphasia secondary to dominanthemisphere infarction, three of whom were available to followup. All three patients had residual expressive aphasia but had regained some comprehension of spoken language and, despite worse communication scores, had similar overall HRQoL and were satisfied. In our opinion, dominant-side malignant MCA territory infarction should not be considered a contraindication to DH given the significant potential for neurological recovery in these patients.

Our study has limitations, including its retrospective nature leading to inherent selection bias and the small number of patients included in the analysis. However, our finding that a consecutive series of patients undergoing $\mathrm{DH}$ for malignant MCA territory infaction were satisfied with their HRQoL and were happy to be alive, justifies at least offering this life-saving procedure to well-selected groups of patients.

\section{Conclusion}

Although many patients may remain dependent and exhibit reduced HRQoL following DH for malignant MCA territory infarction, the majority appear to be satisfied even in the face of moderate-to-severe disability and dominant-hemsiphere stroke. Therefore, dominant-hemisphere malignant MCA territory 
infaction should not be considered a contra-indication to $\mathrm{DH}$. Discussion with patients and their families should emphasize the possibility of severe residual neurological deficits and dependency in daily living, which may nonetheless be associated with satisfactory HRQoL.

\section{REFERENCES}

1. Hacke W, Schwab S, Horn M, Spranger M, De Georgia M, von Kummer R. 'Malignant' middle cerebral artery terriotory infarction: Clinical course and prognostic signs. Arch Neurol. 1996;53(4):309-15.

2. Silver FL, Norris JW, Lewis AJ, Hachinski VC. Early mortality following stroke: a prospective review. Stroke. 1984;15(3): 492-6.

3. Berrouschot J, Sterker M, Bettin S, Köster J, Schneider D. Mortality of space-occupying ('malignant') middle cerebral artery infarction under conservative intensive care. Intensive Care Med. 1998;24(6):620-3.

4. Hofmeijer J, Kappelle LJ, Algra A, HAMLET investigators. Surgical decompression for space-occupying cerebral infarction (the Hemicraniectomy After Middle Cerebral Artery infarction with Life-threatening Edema Trial [HAMLET]): a multicentre, open, randomised trial. Lancet Neurol. 2009;8(4):326-33.

5. Jüttler E, Schwab S, Schmiedek P, DESTINY Study Group. Decompressive Surgery for the Treatment of Malignant Infarction of the Middle Cerebral Artery (DESTINY): a randomized, controlled trial. Stroke. 2007 Sep;38(9):2518-25.

6. Vahedi K, Hofmeijer J, Juettler E, DECIMAL, DESTINY, and HAMLET investigators. Early decompressive surgery in malignant infarction of the middle cerebral artery: a pooled analysis of three randomised controlled trials. Lancet Neurol. 2007;6(3):215-22.

7. Vahedi K, Vicaut E, Mateo J, DECIMAL Investigators. Sequentialdesign, multicenter, randomized, controlled trial of early decompressive craniectomy in malignant middle cerebral artery infarction (DECIMAL Trial). Stroke. 2007;38(9):2506-17.

8. Benejam B, Sahuquillo J, Poca MA, et al. Quality of life and neurobehavioral changes in survivors of malignant middle cerebral artery infarction. J Neurol. 2009;256(7):1126-33.

9. Puetz V, Campos CR, Eliasziw M, Hill MD, Demchuk AM; Calgary Stroke Program. Assessing the benefits of hemicraniectomy: what is a favourable outcome? Lancet Neurol. 2007;6(7):580-1.

10. Sanaldioglu IE, Schoch B, Rauhut F. Hemicraniectomy for large middle cerebral artery territory infarction: do these patients really benefit from this procedure? J Neurol Neurosurg Psychiatry. 2003;74(11):1600.

11. Vahedi K, Benlist L, Kutz A, et al. Quality of life after decompressive craniectomy for malignant middle cerebral artery infarction. J Neurol Neurosurg Psychiatry. 2005;76(8):1181-2.

12. Gladis MM, Gosch EA, Dishuk NM, Critis-Cristoph P. Quality of life: expanding the scope of clinical significance. J Consult Clin Psychol. 1999;67(3):320-31.

13. Carod-Artal FJ, Trizotto DS, Coral LF, Moreira CM. Determinants of quality of life in Brazilian stroke survivors. J Neurol Sci. 2009;284(1-2):63-8.

14. Delashaw JB, Broaddus WC, Kassell NF, et al. Treatment of right hemispheric cerebral infarction by hemicraniectomy. Stroke. 1990;21(6):874-81.

15. Schwab S, Steiner T, Achoff A, et al. Early hemicraniectomy in patients with complete middle cerebral artery infarction. Stroke. 1998;29(9):1888-93.

16. Manawadu D, Quateen A, Findlay JM. Hemicraniectomy for massive middle cerebral artery infarction: a review. Can J Neurol Sci. 2008;35(5):544-50.

17. Rankin J. Cerebral vascular accidents in people over the age of 60 : prognosis. Scott Med J. 1957;2:200-15.
18. Mahoney GI, Barthel DW. Functional evaluation: the Barthel Index. Ms State Med J. 1965;14:61-5.

19. Carod-Artal FJ, Ferreira Coral L, Stieven Trizotto D, Menezes Moreira C. Self- and proxy-report agreement on the Stroke Impact Scale. Stroke. 2009 Oct;40(10):3308-14.

20. Duncan P, Reker D, Kwon S, et al. Measuring stroke impact with the stroke impact scale: telephone versus mail administration in veterans with stroke. Med Care. 2005;43(5):507-15.

21. Duncan PW, Lai SM, Tyler D, Perera S, Reker DM, Studenski S. Evaluation of proxy responses to the Stroke Impact Scale. Stroke. 2002;33(11):2593-9.

22. Duncan PW, Wallace D, Min Lai S, Embretson S. The Stroke Impact Scale Version 2.0: evaluating reliability, validity, and sensitivity to change. Stroke. 1999;30(10):2131-40.

23. Buck D, Jacoby A, Massey A, Ford G. Evaluation of measures used to assess quality of life after stroke. Stroke. 2000;31(8):2004-10.

24. Carod-Artal FJ, Egido JA. Quality of life after stroke: the importance of a good recovery. Cerebrovasc Dis. 2009;27 Suppl 1:204-14.

25. WHOQOL Group. Development of the World Health Organization WHOQOL-BREF quality of life assessment. Psychol Med. 1998;28:551-8.

26. Curry WT Jr, Sethi MK, Ogilvy CS, Carter BS. Factors associated with outcome after hemicraniectomy for large middle cerebral artery territory infarction. Neurosurgery. 2005; 56(4):681-92.

27. Leonhardt G, Wilhelm H, Doerfler A, et al. Clinical outcome and neuropsychological deficits after right decompressive hemicraniectomy in MCA infarction. J Neurol. 2002;249(10): 1433-40.

28. Pohjasvaara T, Leppävuori A, Siira I, Vataja R, Kaste M, Erkinjuntti $\mathrm{T}$. Frequency and clinical determinants of poststroke depression. Stroke. 1998;29(11):2311-17.

29. Walz B, Zimmermann C, Böttger S, Haberl RL. Prognosis of patients after hemicraneictomy in malignant middle Cerebral artery infarction. J Neurol. 2002;249(9):1183-90.

30. Carter BS, Ogilvy CS, Candia GJ, Rosas HD, Buonanno F. Oneyear outcome after decompressive surgery for massive nondominant hemispheric infarction. Neurosurgery. 1997;40(6): 1168-75.

31. Foerch C, Lang JM, Krause J, et al. Functional impairment, disability, and quality of life outcome after decompressive hemicraniectomy in malignant middle cerebral artery infarction. J Neurosurg. 2004;101(2):248-54.

32. Skoglund TS, Eriksson-Ritzén C, Sörbo A, Jensen C, Rydenhag B. Health status and life satisfaction after decompressive craniectomy for malignant middle cerebral artery infarction. Acta Neurol Scand. 2008;117(5):305-10.

33. Woertgen C, Erban P, Rothoerl RD, Bein T, Horn M, Brawanski A. Quality of life after decompressive craniectomy in patients suffering from supratentorial brain ischemia. Acta Neurochir (Wien). 2004;146(7):691-5.

34. Pillai A, Menon SK, Kumar S, Rajeev K, Kumar A, Panikar D. Decompressive hemicraniectomy in malignant middle cerebral artery infarction: an analysis of long-term outcome and factors in patient selection. J Neurosurg. 2007;106(1):59-65.

35. Masuhr KF. Untersuchung psychischer Funktionen. In: Masuhr KF, Neumann M, editors. Neurologie. Stuttgart: Hipokrates;1992. p. 98-110.

36. Kastrau F, Wolter M, Huber W, Block F. Recovery from aphasia after hemicraniectomy for infarction of the speech-dominant hemisphere. Stroke. 2005;36(4):825-9.

37. Rieke K, Schwab S, Krieger D, et al. Decompressive surgery in space-occupying hemispheric infarction: results of an open, prospective trial. Crit Care Med. 1995;23(9):1576-87.

38. Gupta R, Connoly ES, Mayor S, Elking MS. Hemicraniectomy for massive middle cerebral artery territory infarction: a systematic review. Stroke. 2004;35(2):539-43. 